\title{
Challenges experienced by parents living with a child with attention deficit hyperactivity disorder
}

\author{
Meisie Mofokeng and Anna E van der Wath \\ Department of Nursing Science, University of Pretoria, Pretoria, South Africa \\ *Corresponding author, email: annatjie.vanderwath@up.ac.za
}

\begin{abstract}
Objective: The aim of this South African study was to explore parents' experiences of living with a child with attention deficit hyperactivity disorder (ADHD).

Methods: A qualitative research design was followed. Purposive sampling was used to select ten parents living with children diagnosed with ADHD receiving outpatient treatment at a psychiatric facility. Data, collected through unstructured individual interviews, were analysed using open coding. Measures to ensure trustworthiness and ethical research practices were applied.
\end{abstract}

Results: Five themes emerged: burden of care; emotional effects; social effects; impact of the educational challenges, and attempts to cope with the burden of care.

Conclusion: Parents living with a child with ADHD experience stress as they struggle to cope with the child's symptoms amidst the stigmatising attitudes from family and community members. Parents experience burdensome emotions and impaired social and occupational functioning. Health care practitioners need to take note of the challenges inherent to parenting a child with ADHD in order to provide multi-disciplinary interventions aimed at empowering and supporting parents.

Keywords: ADHD, parenting challenges, parenting styles

\section{Introduction}

In children, attention deficit hyperactivity disorder (ADHD) is characterised by a persistent pattern of inattention, hyperactivity, and impulsivity. In many cases, ADHD is accompanied by one or more psychiatric comorbidities and/or functional impairments (American Psychiatric Association, 2013; Tarver et al., 2014). A literature review by Baxter (2013) indicated that the symptoms and behaviour associated with ADHD, place strain on families and lead to an increased rate of dysfunction in family units. Parents of children with ADHD experience higher rates of parenting stress than parents of children without ADHD (Theule et al., 2013). Parental stress is exacerbated by co-occurring conduct problems, ADHDcombined presentation (Tzang et al., 2009), and when the child is not medicated for ADHD (Moen et al., 2016).

Parents' responses towards their children with ADHD have reciprocal effects. Parents' frustration with their children may exacerbate acting-out behaviour (Mitchell, 2013). The tendency of these parents to follow less permissive and more authoritarian parenting styles leads to the worsening of ADHD symptoms (Moghaddam et al., 2013), and to the secondary development of other behavioural disorders in children with ADHD (Texeira et al., 2015). The mentioned parental responses as well as parental psychopathology may interfere with treatment compliance in children with ADHD. It follows that healthcare providers need to 
assess parental stress, include the findings in treatment planning, and develop interventions for parents (Tzang et al., 2009). Improving parenting styles with a variety of interventions can improve quality of life and relationships in families with ADHD children (Moghaddam et al., 2013).

Through her work as a psychiatric nurse, the first author (MM) became aware that the parents of children with ADHD who attended the outpatient clinic of a psychiatric facility in South Africa experienced severe stress. When they brought their children for treatment and follow-up, they often verbalised that they feel demotivated and tired. Some parents requested inpatient admission and re-admission for their children to relieve the stress at home. Although only children who required treatment revision due to co-morbid conditions, and/or disruptive social circumstances were admitted (according to institutional policy), the number of children re-admitted with ADHD increased from 20 in 2008 to 40 in 2011. Some children were admitted three to four times a year for extended periods of three to six months. The situation stretched the financial and human resources of the facility.

Research should address recidivism and readmission to inpatient care in children with psychiatric disorders, as it may reflect a lack of appropriate community care (Rüth et al., 2013). A study comparing the views of parents and practitioners on effective early parenting interventions for ADHD, highlighted a need to increase awareness of parental psychological barriers among practitioners (Smith et al., 2014). Parents most often coordinate the care of their children with ADHD across primary care, specialty mental health care, and educational settings. Family-centred models for ADHD could help families to access and utilise care settings more effectively (Davis et al., 2012).

The present study aimed to explore the experiences of parents living with children with ADHD who receive outpatient treatment at a psychiatric facility. The research was guided by the following research question: What are the experiences of parents living with children with ADHD who receive outpatient treatment at a psychiatric facility?

\section{Methods}

A descriptive qualitative design was used to explore parents' experiences in an in-depth manner. The research was conducted at the outpatient clinic of a public psychiatric facility in an urban area in South Africa. This facility has a child and family unit where 15 children can be admitted as inpatients. Additionally, the facility has an outpatient clinic where follow-up care is provided to children with mental health problems.

Only parents of children between the ages of six to 12 years who were assessed by a psychiatrist and diagnosed with ADHD according to DSM IV criteria were considered for selection. The researcher requested the healthcare professionals who the parents consult with at the outpatient clinic to refer potential participants to her. Sample size was determined by data saturation (Polit \& Beck, 2012). Themes started to repeat themselves by the eighth interview and no new themes emerged. The researcher did two more interviews to ensure saturation.

The purposively selected sample consisted of two males and eight females from Tshwane District. Their ages ranged between 25 and 50 . All the children (six males and four females) were on treatment and their parents experienced concerns about their behaviour for periods ranging between five to ten years. No mention was made on the case files of parental psychopathology. The parents were mostly from a lower socio-economic status as the study was conducted at a public hospital.

The researcher used unstructured interviews, a data collection method designed to allow participants to narrate their experiences without a set of prepared questions. Participants 
discussed their challenges with little interruption. The interview data were supplemented by field notes reflecting the researcher's observations of participants' non-verbal communication (Polit \& Beck, 2012).

The parents were interviewed when they brought their children for follow-up treatment at the outpatient clinic. The interviews were conducted at a consultation room at the outpatient clinic, ensuring privacy. The researcher obtained informed consent from participants and asked one central open-ended question to explore their experiences: "What are your experiences as a parent living with a child diagnosed with attention deficit hyperactivity disorder?" The central question was followed by open-ended probing questions to allow for a rich description of the research phenomenon (Polit \& Beck, 2012). Guided by the participants' responses, applicable probing questions were formulated, for example, "Tell me more...; May you clarify the statement...; I wonder about....?" Although all participants were conversant with their children's diagnosis, the researcher provided explanations when participants seemed not to be clear about the meaning of ADHD.

The criteria of credibility, conformability, transferability, dependability, and authenticity (Polit \& Beck, 2012) were applied to ensure trustworthiness of the results. Approval for the research procedures was obtained from the Research Ethics Committee of the Faculty of Health Sciences at the University of Pretoria, and from the management of the psychiatric facility.

Open coding was used to analyse the data (Tesch, 1992). The recorded interviews were transcribed. The researcher and an independent coder, experienced in qualitative data analysis, independently analysed the data. The process entailed reading through the data to obtain a general sense of and reflect on the overall meaning. Phrases with similar meanings were segmented as themes and labelled with a term describing the experience reflected by the participant. All the data were coded according to the themes that emerged as parents' experiences. The researcher and coder met to reach consensus on the themes.

\section{Results}

Five themes emerged: burden of care, emotional effects, social effects, the impact of educational challenges, and attempts to cope with the burden of care. The themes are substantiated with verbatim quotations and field notes in brackets.

\section{Burden of care}

Living with a child with ADHD was described by participants as a demanding and stressful experience. The stress experienced sometimes caused sleeping problems: "I didn't even sleep, I was telling myself: maybe I will be on treatment, even now I am not happy, actually I am stressed [cried and appeared disturbed]" (participant 9, female). Another participant experienced physical pain: "I have to shout from morning until the afternoon, my whole body is painful" (participant 4, female).

Participants experienced the caregiving as a burden that consumes their resources:

It affects me a lot because there is a lot I carried on my shoulder...I don't feel like I have the life of my own, I have got a family to look after...household chores... a husband who is working...other grandchildren, other children...I can't live my life around one child [sighed and appeared exhausted] (participant 2, female).

The participants linked the burden of care to the challenging behaviour a child with ADHD often presents with: "He is noisy and rude, he backchats, he is never sitting down, he is 
always busy with other kids doing something than to work, and he beats other kids" (participant 3, female).

Participants never knew what to expect: "...you don't know when the school is going to call and when the parents are going to call... it is stressful...." (participant 3, female). The participants struggled to understand the child's unpredictable behaviour:

...he will start playing like a little boy should play, I don't know what switches off or on his mind, he will end up bullying...or hurting other kids...being aggressive towards other kids, he will try chances...he will be defiant towards the other kids...he just ruins playtime [frowned and appeared angry] (participant 1, male).

\section{Emotional effects}

With regards to the emotional effects of living with a child with ADHD, the next two participants described frustration and helplessness: "...really it is frustrating I have other children to attend to..." (participant 1, male), and "...very frustrating and difficult, sometimes you don't understand, it leaves you like helpless..." (participant 10, female).

Participants verbalised feelings of depression and sadness: "I was very sad and very disappointed; I can't even accept it anymore" (participant 9, female). The following participant experienced a disturbed sleeping pattern and physical symptoms that she interpreted as depression: "It makes me feel, I don't understand how to say this, it makes me depressed, even at night I was sick... I had pains all over my body, from my leg I have this pain..." (participant 4, female).

Most participants experienced feelings of anger: "I am angry about it; it makes me angry because he is going back on medication" (participant 9, female). The following two participants, who were both committed and caring towards their children, linked their anger to the responses of other people towards their children:

...no matter what he does; he is always on the wrong side.

Sometimes it is somebody else who did something, his name is going to be mentioned or put forward. It angers me and upsets me... (participant 4, female).

I am sad and... angry and then I just want to take her away from this people who doesn't treat her right (participant 10, female).

The next participant expressed her anger as an urge to harm somebody: "It bothered me when someone tells you, your child is stupid; I wanted to strangle the teacher..." (participant 4 , female).

\section{Social effects}

Having a child with ADHD disrupts the social functioning of the family on different levels. The child's challenging behaviour affects relationships with siblings and peers:

...he can play only for five minutes, after five minutes there is a big fight and he beats other kids...for just few minutes he's fine and then...he starts to fight his sister or young brother and now his young brother is scared of him (participant 4, female).

In the following quotation the participant explained how her child was rejected and stigmatised by both family and community members:

They don't want my child near them...she [a friend] banged the door behind my child, everybody rejects her even the dominee [minister] in my church...my sisters cannot accept my child, they don't buy her presents, they don't want to see her... always talk bad about her. My husband could not handle the child (participant 2, female). 
The next two participants explained how their families experienced social isolation: "...we didn't go to our families' gatherings and meeting because they do not accept my child as she is..." (participant 10, female), and "You feel isolated, you can't visit people, you don't know what he is going to do; sometimes he breaks things and hides them..." (participant 7, female).

\section{The impact of educational challenges}

Participants expressed their struggles with the educational system. They received constant negative reports and complaints from the school: "...they complain about his behaviour, that he doesn't do anything, he doesn't do his work..." (participant 3, female). The complaints reflected a lack of understanding from teachers: "...they told me that the child was insulting and fighting with other children...they take it she was naughty" (participant 6 , female). The next quotations reflect negativity and rejection towards the child:

...she was struggling with reading and writing...one teacher said she is a stupid child... (participant 6 , female) ...he was rejected...they [the school] send him there and there...they keep on sending him back (participant 1 , male) ...there is negativity towards him from the school side...(participant 3 , female).

Participants explained the anguish they went through to find appropriate schools for their children: "...we had to go through a lot of red tape to get the child to a special school and had to wait for a long time because there was a waiting list as well" (participant 9, female). One of her children ended up not going to school while the participant struggled to find a school equipped to provide in the child's special needs: "...from January to March - he never attended school...I had to go to the Department of Education for a referral letter so that the other school can admit him..." (participant 4, female).

Some participants narrated how the burden of care affected their occupational functioning: "... since they told me about the ADHD, even at work I don't have energy, it is like...I am sick, also I don't work, I don't have energy, it is not me..." (participant 9, female). The next participant had to give up her work: "I am not working anymore...she couldn't cope without me. It was only she and her father at home and it was difficult..." (participant 10, female).

\section{Attempts to cope with the burden of care}

Some participants clearly stated: "I was not coping..." (participant 8 , female). Participants found it difficult to cope with the challenging behaviour associated with ADHD, for example, anger: "I can cope and will always cope with my child but I can't handle the tantrums" (participant 2, female). In spite of her husband saying: "the child is extremely disabled he can't cope with him...," this participant stated: “...we must just cope” (participant 7, female). Another participant suppressed her feelings: "...I can't cope anymore like that you see, but I don't show it" (participant 10, female).

Attempts to cope included different ways used by the participants to manage their children's behaviour. Such attempts included:

i) Channelling energy: “...he is running a lot, it makes us mad and sometimes I take him out and give him some work to do for his energy..." (participant 5, male).

ii) Time-out: "He was in his room or in the corner because he does not want to listen..." (participant 1, male).

iii) Withdrawing privileges: "I catch them fighting...I take their privileges..." (participant 1, male). 
iv) Monitoring and routine: "...he knows his place...you need to check if he is doing the right things and at the correct time. We try to keep a schedule of what to be done and when to be done and try to adhere to it..." (participant 3, female).

v) Punishment: "...I have to punish him so that he can listen, so he does not listen to my mother...to my sister or to my younger brother" (participant 4, female).

vi) Corporal punishment: “...I took a belt and hit her...I must discipline her" (participant 10, female).

However, on participant realised that punishment accompanied with anger may worsen the child's behaviour:

...you can't scream at them you can't hit them, you've got to talk to

them... and not raise your voice. Once you raise your voice, they

switch off, so talk quietly like a very ordinary conversation and it doesn't matter how cross you are to hold it in, so they don't get these

vibes, so it doesn't set them off more (participant 9, female).

Another participant refrained from using corporal punishment as she felt the child is not to blame for her behaviour: "Sometimes I get angry...I would want to hit her, but tell myself not to because it is wrong and it is not her fault..." (participant 6, female).

Some participants managed to mobilise social support as a way of coping: “...we are a very close-knit family...I can ask them to babysit and to fetch him from school...they are actively involved..." (participant 3, female). Similarly, others said: "They are very supportive, my family, my work...and the school..." (participant 7, female), and "...people at church are very loving and very kind to her..." (participant 10, female). Support from Participant four's (female) work when she needed time off, helped her to cope: "I can cope, I started working now...it is only 4 days in and 4 days off...they understand my situation..."

Other participants coped through accepting and loving their children in spite of all the challenges: "... she is not an easy child, we love her and cannot abandon her because she has got a problem" (participant 6, female). Along the same lines, Participant 10 (female) said: "But we try our level best to give her the love and acceptance and what we can give her..." Spirituality provided some participants with the strength to cope: "...maybe it is with the help of God that we as parents can cope because we love her to bits, very, very much and she is our only daughter..." (participant 10, female).

\section{Discussion}

Similar to the experiences of parents in this article, Norwegian parents of children with ADHD (Moen et al., 2011) related experiences of despair, sorrow, and powerlessness that sometimes felt similar to a grieving process. This stressful situation led some parents to divorce or put their careers on hold. Although parents of children not medicated for ADHD seemed most vulnerable to the psychological distress associated with the burden of care (Moen et al., 2016); Sikirica and colleagues (2015) highlighted that multiple unmet needs might persist despite children being on treatment. The burden of care significantly affects parents' well-being and/or mental health. In a study by Davis and colleagues (2012), 39\% of parents with a child with ADHD reported symptoms of stress and worry leading to mental health problems. Fernandes and colleagues (2015) indicated that higher levels of stress about parenting were associated with parents perceiving themselves to be less accepting and having lower levels of quality of life. The burden of care highlights the importance of supporting parents in dealing with stress. 
Moen and colleagues (2016) recommend interventions to address parental stress, selfesteem, and locus of control. Multi-disciplinary support for the entire family is important. Engagement of fathers in the child's care may help ease the burden of care on mothers, and was found to be associated with a decrease in aggression in children with ADHD (Mitchell, 2013). However, it should be noted that both the fathers and mothers interviewed in this study experienced similar burdens.

Parents in this study experienced emotional effects such as anger and frustration. Lambek and colleagues (2015) found that inattention symptoms evoked the strongest emotional response in parents, followed by impulsivity. The study by Theule and colleagues (2013) found that both inattention and hyperactive-impulsive symptoms affected parenting stress. However, inattentive symptoms were associated with less family disruption.

ADHD is associated with substantial impairment in social and peer functioning (Tarver et al., 2014). In this study families experienced social isolation and impairment in internal and external family relationships. Moen and colleagues (2016) found that characteristics in both parents (well-being and psychological distress) and in children (behaviour of the child) influenced families' social functioning.

Some of the social effects parents experienced can be related to the societal stigma attached to ADHD. This stigma is well described in the literature (Lebowitz, 2016; Moldavsky \& Sayal, 2013). Being stigmatised increases the effects of parental stress, compound the burden of care, and may become a self-fulfilling prophesy (Garcia \& Goodfriend, 2015). Mukolo and colleagues (2010) identified three dimensions of stigma (negative stereotypes, devaluation, and discrimination), two contexts of stigma (self, and general public), and two targets of stigma (self/individual, and family). An example where the family is stigmatised is when society puts a judgement on parents with a child with a diagnostic label such as ADHD. Yet, Ohan and colleagues (2013) found that the stigma is usually primarily due to the symptoms, not the label. In this study parents experienced rejection and stigmatisation from family and community members related to their children's disruptive behaviour.

Mikami and Normand (2015) argue that not only the inappropriate behaviour of children with ADHD contribute to problematic peer relationships, but also peer group factors. These factors include social devaluation explained by the stigma associated with ADHD, exclusionary behaviour evidenced in rejection, and reputational bias based on the impressions children have of each other. Programmes where children with ADHD and their parents participate to learn social skills such as conflict resolution and peer group entry, may improve children's peer functioning domains (Gardner et al., 2015).

Some parents in the study reported occupational impairment due to a lack of energy and the time they needed to spend with the child with ADHD. Similarly, Oruche and colleagues (2015) and Sikirica and colleagues (2015) reported that caregivers of children with ADHD experienced stress about the personal sacrifices they had to make; including giving up time to engage in own activities, and being gainfully employed.

Parents in the study explained the impact of the educational challenges their children experienced. Previous research indicates that $84 \%$ of caregivers reported how ADHD symptoms affected the children's school performance, while $71 \%$ reported disciplinary problems with the children at school (Sikirica et al., 2015). Regarding the stigmatising attitudes displayed by some teachers in this study, educational interventions to improve the knowledge of teachers about ADHD appeared to be effective in the short term (Moldavsky \& Sayal, 2013). 
As evidenced in this study, the different ways parents attempt to cope with a child with ADHD may be reflected in their parenting styles. Alizadeh and colleagues (2007) found that these parents tend to have lower self-confidence and less warmth and involvement with their children, and use corporal punishment significantly more than other parents, putting children with ADHD at considerable risk of abuse. However, it should be noted that this particular study excluded all children on treatment. Authoritarian parenting, a parenting style characterised by high demands and low responsiveness, was related to lower implicit selfesteem among children with ADHD. The level of implicit self-esteem among children with ADHD is linked to support and warmth. Authoritarian parents have high expectations, yet provide little feedback and nurturance (Kurman et al., 2015). Significant associations were found between maternal hostility and child ADHD symptoms (Harold et al., 2013). Some of the parents in this study were punitive towards their children, but others realised that being supportive and patient yielded better results.

Promotion of effective parenting styles such as training in responsiveness strategies and behaviour modification methods, decreased authoritarian and neglectful parenting scores (Kurman et al., 2015) and reduced depression symptoms among mothers of children with ADHD (Kordestani et al., 2014). Therapists facilitating parenting programmes for use with preschool children with ADHD should facilitate the changes parents are required to make and address the parents' needs in addition to those of the child for the programme to be beneficial (Smith et al., 2014).

Similar to some participants in this study, parents of children with ADHD in a study by Fernandes and colleagues (2015) perceived themselves as accepting of their children. The same study also found that parents who feel less stressed about parenting, perceived themselves as accepting of their children.

\section{Implications}

To relief the burden of care, case specific psychoeducation to empower both parents and all caregivers with knowledge about ADHD (symptoms and implications) as well as available treatment options, is recommended. Ideally parents should be given a pamphlet with concise and clear explanations (Ahmed et al., 2014; Michielsen et al., 2015; Wright et al., 2015). Ahmed and colleagues (2014) suggest that parents take a list of prepared questions (prompt lists) with them during consultations as a way of obtaining relevant information tailored to their child's needs.

The following treatment options are recommended (as applicable, with parents' consent and assent):

i) Diagnosis and treatment of co-morbidities.

ii) Liaison with the educational system to identify and address educational aspects and ensure appropriate school placement and regular feedback from teachers. Children with ADHD in the study context are accommodated in mainstream education as far as possible. Since completion of this study, the institution is offering programmes to support educators in the management of children with mental health problems.

iii) Psychiatric medication management and referral for special investigations.

iv) Parental counselling for both parents to encourage authoritative parenting styles and consistent parenting.

v) Management of parental psychopathology.

vi) Management of concerns regarding abuse or neglect.

vii) Appropriate referral to allied services, for example, occupational therapist, social worker and psychologist to address concerns through individual and therapeutic group interventions. 
Recommendations for further research include quantitative research to investigate specific issues such as parents' stress levels and depressive symptomatology; and mental health care professionals' perceptions of treatment effectiveness compared to those of parents.

\section{Conclusion}

Living with a child with ADHD is challenging. Parents struggle to cope with the child's unpredictable behaviour and symptoms. Moreover, they experience stigmatising attitudes from the people who are expected to be supportive; their own families, teachers, and community members. Parents experience burdensome emotions such as anger, frustration, helplessness, depression, and impaired social and occupational functioning. Parents' responses to these challenges might affect their parenting styles which may in turn exacerbate the child's ADHD symptoms and lead to recidivism and readmission to inpatient psychiatric treatment. It is clear that health care practitioners need to take note of the challenges inherent to parenting a child with ADHD and adapt their treatment programs to include multi-disciplinary interventions aimed at empowering and supporting parents.

\section{Limitations}

The study explored the experiences of a small sample parents in a very specific context. Some of the challenges the parents experienced might apply to under-resourced countries only, for example the educational challenges. The researcher did not explicitly exclude parents of children with co-morbid conditions from the study. Experiences pertaining to these conditions might be reflected in some of the findings.

The study did not include information about participants' partner status or socio-economic status, variables that are likely to moderate the challenges of caring for a child with ADHD. The authors suggest that further research on coping with the demands of children with ADHD and other challenging conditions should include background variables likely to influence the carer's resources and coping.

\section{References}

Ahmed, R., Borst, J. M., Yong, C. W. \& Aslani, P. (2014). Do parents of children with attentiondeficit/hyperactivity disorder (ADHD) receive adequate information about the disorder and its treatments? A qualitative investigation. Patient Preference and Adherence, 8, 661-670. http://dx.doi.https://doi.org/10.2147/PPA

Alizadeh, H., Applequist, K. F., \& Coolidge, F. L. (2007). Parental self-confidence, parenting styles, and corporal punishment in families of ADHD children in Iran. Child Abuse \& Neglect, 31(5), 567-572. https://doi.org/10.1016/i.chiabu.2006.12.005

American Psychiatric Association. (2013). DSM-5 attention deficit/hyperactivity disorder fact sheet. Retrieved from http://www.dsm5.org/documents/adhd\%20fact\%20sheet.pdf 15

Baxter, J. L. (2013). The effects of ADHD on the family unit. (Master's Thesis). Washington State University, Washington USA.

Davis, C. C., Claudius, M., Palinkas, L. A., Wong, J. B. \& Leslie, L. K. (2012). Putting families in the center: Family perspectives on decision making and ADHD and implications for ADHD care. Journal of Attention Disorders, 16(8), 675-684. http://dx.doi.https://doi.org/10.1177/1087054711413077

Fernandes, S. S., Machado, M., \& Machado, F. (2015). Parental acceptance, parental stress, and quality of life: A study with parents of ADHD children. Journal of Special Education for Inclusion, III(1), 71-83.

Garcia, E., \& Goodfriend, W. (2015). Outsiders' perceptions and stigmas for parents with ADHD children. Journal of Psychological Inquiry, 20(2), 81-90. 
Gardner, D. M., Gerdes, A. C. \& Weinberger, K. (2015). Examination of a parent-assisted, friendship-building program for adolescents with ADHD. Journal of Attention Disorders, 1-11. http://dx.doi.https://doi.org/10.1177/1087054715588188

Harold, G. T., Leve, L.D., Barrett, D., Elam, K., Neiderhiser, J. M., Natsuaki, M. N., Shaw, D. S., Reiss, D. \& Thapar, A. (2013). Biological and rearing mother influences on child ADHD Symptoms: Revisiting the developmental interface between nature and nurture. Journal of Child Psychology and Psychiatry, 54(10), 1038-1046. http://dx.doi.https://doi.org/10.1111/jcpp.12100

Kordestani, D., Khalili-Sadrabad, A., Salari, M., Amiri, M., \& Motavallipor, A. (2014). The effect of behavioral parent training on alleviation of depression symptoms and improving parenting styles of mothers with ADHD children. Journal of Behavioral Sciences, 8(1), 47-54.

Kurman, L., Rothschild-Yakar, L., Angel, R. \& Katz, M. (2015). How good am I? Implicit and explicit selfesteem as a function of perceived parenting styled among children with ADHD. Journal of Attention Disorders, advanced online publication. http://dx.doi.https://doi.org/10.1177/1087054715569599

Lambek, R., Sonuga-Barke, E., Psychogiou, L., Thompson, M., Tannock, R., Daley, D., . . Thomsen, P. (2015). The parental emotional response to children index: A questionnaire measure of parents' reactions to ADHD. Journal of Attention Disorders, 3, 1-14.

Lebowitz, M. S. (2016). Stigmatization of ADHD: A developmental review. Journal of Attention Disorders, 20(3), 240-250. https://doi.org/10.1177/1087054712475211

Michielsen, M., de Kruif, J. Th. C. M., Comijs, H. C., van Mierlo, S., Semeijn, E. J., Beekman, A. T. F., Deeg, D. J. H. \&. Kooij J. J. S. (2015). The burden of ADHD in older adults: A qualitative study. Journal of Attention Disorders, advanced online publication. http://dx.doi.https://doi.org/10.1177/1087054715610001

Mikami, A. Y. \& Normand, S. (2015). The importance of social contextual factors in peer relationships of children with ADHD. Current developmental disorders reports, 2(30). http://dx.doi.https://doi.org/10.1007/s40474-014-0036-0

Mitchell, K. L. (2013). The importance of the parent-child relationship in the protection against behaviour problems in children with ADHD (Masters Thesis). University of Calgary, Calgary, Alberta.

Moen, O. L., Hall-Lord, M. L., \& Hedelin, B. (2011). Contending and adapting every day: Norwegian parents' lived experience of having a child with ADHD. Journal of Family Nursing, 17(4), 441-462. https://doi.org/10.1177/1074840711423924

Moen, O. L., Hedelin, B. \& Hall-Lord, M. L. (2016). Family functioning, psychological distress, and well-being in parents with a child having ADHD. SAGE Open, January-March 2016, 1-10. http://dx.doi.https://doi.org/10.1177/2158244015626767

Moghaddam, M. F., Assareh, M., Heidaripoor, A., Eslami Rad, R., \& Pishjoo, M. (2013). The study comparing parenting styles of children with ADHD and normal children. Archives of Psychiatry and Psychotherapy, 15(4), 45-49. https://doi.org/10.12740/APP/19375

Moldavsky, M., \& Sayal, K. (2013). Knowledge and attitudes about attention-deficit/ hyperactivity disorder (ADHD) and its treatment: The views of children, adolescents, parents, teachers and healthcare professionals. Current Psychiatry Reports, 15(8), 377-384. https://doi.org/10.1007/s11920-013-0377$\underline{0}$

Mukolo, A., Heflinger, A., \& Wallston, K. A. (2010). The stigma of childhood mental disorders: A conceptual framework. Journal of the American Academy of Child and Adolescent Psychiatry, 49(2), 192-198.

Ohan, J. L., Visser, T. A. W., Moss, R. G., \& Allen, N. B. (2013). Parents' stigmatizing attitudes toward psychiatric labels for ADHD and depression. Psychiatric Services (Washington, D.C.), 64(12), 12701273. https://doi.org/10.1176/appi.ps.201200578

Oruche, U. M., Draucker, C. B., Al-Khattab, H., Cravens, H. A., Lowry, B., \& Lindsey, L. M. (2015). The challenges for primary caregivers of adolescents with disruptive behavior disorders. Journal of Family Nursing, 21(1), 149-167. https://doi.org/10.1177/1074840714562027

Polit, D. F., \& Beck, C. T. (2012). Nursing research: Generating and assessing evidence for nursing practice (8th ed.). Philadelphia: Lippincott. Williams \& Wilkins. 
Rüth, U., Freisleder, F. J., \& Heinrich, H. (2013). Outpatient emergency admissions to a child and adolescent psychiatry hospital, and following immediate hospitalization. German Journal of Psychiatry, 16(1), 16.

Sikirica, V., Flood, E., Dietrich, C. N., Quintero, J., Harpin, V., Hodgkins, P., . . Erder, M. H. (2015). Unmet needs associated with attention-deficit/hyperactivity disorder in eight European countries as reported by caregivers and adolescents: Results from qualitative research. Patient, 8(3), 269-281. https://doi.org/10.1007/s40271-014-0083-y

Smith, E., Koerting, J., Latter, S., Knowles, M. M., McCann, D. C., Thompson, M., \& Sonuga-Barke, E. J. (2014). Overcoming barriers to effective early parenting interventions for attention-deficit hyperactivity disorder (ADHD): Parent and practitioner views. Child: Care, Health and Development, 41(1), 93-102. https://doi.org/10.1111/cch.12146

Tarver, J., Daley, D., \& Sayal, K. (2014). Attention-deficit hyperactivity disorder (ADHD): An updated review of the essential facts. Child: Care, Health and Development, 40(6), 762-774. https://doi.org/10.1111/cch.12139

Teixeira, M. C. T. V., Marino, R., L. de F. \& Carreiro, L. R. R. (2015). Associations between inadequate parenting practices and behavioral problems in children and adolescents with attention deficit hyperactivity disorder. The Scientific World Journal, 2015, 1-6. http://dx.doi.org/https://doi.org/10.1155/2015/683062

Tesch, R. (1992). Qualitative research: Analysis types and software tools. New York: Falmer.

Theule, J., Wiener, J., Tannock, R., \& Jenkins, J. M. (2013). Parenting stress in families of children with ADHD: A meta-analysis. Journal of Emotional and Behavioral Disorders, 21(1), 3-17. https://doi.org/10.1177/1063426610387433

Tzang, R., Chang, Y., \& Liu, S. (2009). The association between children's ADHD subtype and parenting stress and parental symptoms. International Journal of Psychiatry in Clinical Practice, 13(4), 318-325. https://doi.org/10.3109/13651500903094567

Van der Oord, S., Bögels, S. M. \& Peijnenburg, D. (2012). The effectiveness of mindfulness training for children with ADHD and mindful parenting for their parents. Journal of Child and Family Studies, 21(1). 139-147. http://dx.doi.https://doi.org/10.1007/s10826-011-9457-0

Wright, N., Moldavsky, M., Schneider, J., Chakrabarti, I., Coates, J., Daley, D., . . Sayal, K. (2015). Practitioner review: Pathways to care for ADHD - a systematic review of barriers and facilitators. Journal of Child Psychology and Psychiatry, and Allied Disciplines, 56(6), 598-617. https://doi.org/10.1111/jcpp.12398 